\title{
Impact of lifestyle and technology developments on sleep
}

\author{
This article was published in the following Dove Press journal: \\ Nature and Science of Sleep \\ 5 March 2012 \\ Number of times this article has been viewed
}

\section{Tamar Shochat \\ Department of Nursing, Faculty of Social Welfare and Health Sciences, University of Haifa, Haifa, Israel}

Correspondence: Tamar Shochat, Department of Nursing, Faculty of Social Welfare and Health Sciences, University of Haifa,

Mount Carmel, 31905, Israel

$\mathrm{Tel}+97248288010$

Fax+972482880I7

Email tshochat@univ.haifa.ac.il
Abstract: Although the physiological and psychological mechanisms involved in the development of sleep disorders remain similar throughout history, factors that potentiate these mechanisms are closely related to the "zeitgeist", ie, the sociocultural, technological and lifestyle trends which characterize an era. Technological advancements have afforded modern society with 24-hour work operations, transmeridian travel and exposure to a myriad of electronic devices such as televisions, computers and cellular phones. Growing evidence suggests that these advancements take their toll on human functioning and health via their damaging effects on sleep quality, quantity and timing. Additional behavioral lifestyle factors associated with poor sleep include weight gain, insufficient physical exercise and consumption of substances such as caffeine, alcohol and nicotine. Some of these factors have been implicated as self-help aids used to combat daytime sleepiness and impaired daytime functioning. This review aims to highlight current lifestyle trends that have been shown in scientific investigations to be associated with sleep patterns, sleep duration and sleep quality. Current understanding of the underlying mechanisms of these associations will be presented, as well as some of the reported consequences. Available therapies used to treat some lifestyle related sleep disorders will be discussed. Perspectives will be provided for further investigation of lifestyle factors that are associated with poor sleep, including developing theoretical frameworks, identifying underlying mechanisms, and establishing appropriate therapies and public health interventions aimed to improve sleep behaviors in order to enhance functioning and health in modern society.

Keywords: sleep, technology, lifestyle, behavior

\section{Introduction}

The discipline of modern sleep medicine is dated back to the early 1950 s, following the discovery of rapid eye movement (REM) sleep and the identification of nightly sleep stage distribution. ${ }^{1,2}$ While much basic and clinical research has been done in the past six decades, advancing our understanding of the etiology and mechanisms underlying sleep disorders on the one hand, and enabling the application of clinical diagnosis and treatment practices on the other, it is important to keep in mind that sleep disorders existed and were described long before the mid-20th century.

Ancoli-Israel $^{3}$ has investigated references to sleep in the Bible and the Talmud, regarding the function of sleep, the consequences of both sleep deprivation and excessive sleep, factors involved in the development of insomnia, as well as indications for its cures and treatments. Kryger ${ }^{4,5}$ referred to descriptions of sleep apnea in ancient Greek writings, and in the 19th century novelist Charles Dickens' The Pickwick Papers; 
and both Lavie $^{6,7}$ and Guilleminault ${ }^{8}$ explored 19th century landmark reports of sleep apnea in the medical literature.

Clearly, sleep disorders are "nothing new under the moon", ${ }^{6}$ and the physiological and psychological mechanisms involved in their development remain similar throughout history. For example, Ancoli-Israel ${ }^{3}$ provides several quotes from the Bible regarding anxiety, stress and anguish in relation to sleeplessness; indeed, these are some of the same factors which are associated with the development of insomnia today. ${ }^{9-11}$

Nevertheless, factors that potentiate the mechanisms involved in the development of sleep disorders are closely related to the "zeitgeist", ie, the sociocultural, technological and lifestyle trends which characterize an era. One salient demonstration of such factors refers to shift work, which has evolved from the 24/7 lifestyle enforced in modern societies. Shift work imposes a continuous misalignment between endogenous circadian (24-hour) rhythms and the environmental light/dark cycle. Such desynchrony in physiological and behavioral circadian rhythms has been shown to cause sleep loss and sleepiness, and to detrimentally affect mental performance, safety and health. ${ }^{12,13}$ Similar consequences may be found in cases of jet lag, yet another circadian rhythm disorder, which has become prevalent due to the vast expansion of transmeridian travel. ${ }^{12,14}$

Other modern lifestyle factors affecting sleep are also closely linked to advances in modern technology, enabling and indeed encouraging later bedtimes and longer hours of nighttime arousal; eg, electronic media devices such as television and computers. ${ }^{15-17}$ Yet other factors that interfere with normal sleep/wake patterns include substances such as caffeine, nicotine, alcohol, and drugs, which are commonly consumed in attempts either to maintain alertness and arousal, or to achieve sleepiness and tranquility. ${ }^{15,18-23}$ Lifestyle changes in dietary and physical activity habits and the increased prevalence of overweight and obesity in modern society are also associated with sleep deprivation and disturbance. ${ }^{24-26}$

The aim of this review is to highlight current lifestyle trends that have been shown in scientific investigations to be associated with sleep patterns, sleep duration and sleep quality. Available therapies used to treat some lifestyle related sleep disorders will be discussed. Future perspectives will be provided for the investigation of lifestyle factors that are associated with poor sleep, in terms of understanding the underlying mechanisms, as well as establishing appropriate therapies and public health interventions for their treatment.

\section{Lifestyle trends associated with altered sleep patterns}

The following sections will provide a review of the available investigations suggesting associations between various current lifestyle factors and sleep disturbances. Underlying mechanisms as well as some of the consequences of sleep disturbances related to lifestyle factors will also be discussed.

In an attempt to conceptualize these relationships, a hypothetical model is presented, elaborating the factors associated with chronic interference with sleep patterns in the modern world (see Figure 1). This model divides lifestyle factors into

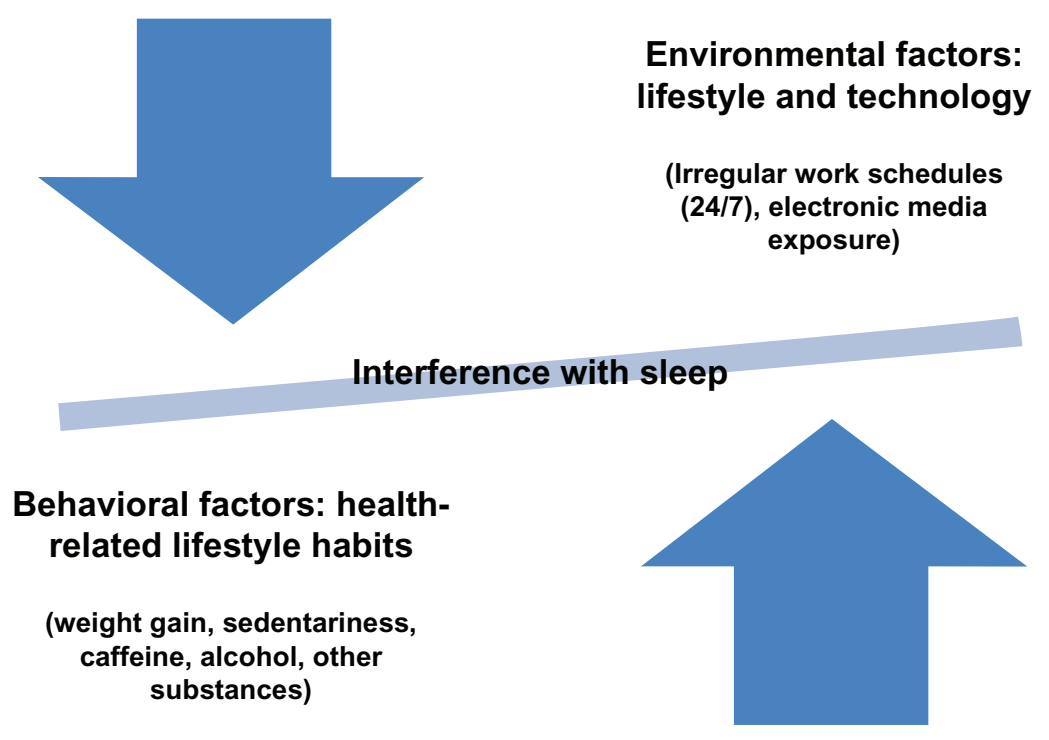

Figure I Schematic model conceptualizing the lifestyle factors that impinge on sleep, and distinguish between environmentally imposed technology-related lifestyle factors and behavioral lifestyle factors that may be considered as habits or countermeasures in response to environmental changes. Both categories ultimately create an imbalance in sleep quality, quantity and timing. 
those that have emerged from environmental technological developments that disrupt normative sleep patterns, and those that may be viewed as behavioral habits, that may serve as countermeasures aimed to combat the deleterious consequences of sleep loss and sleepiness.

\section{Technological developments and circadian desynchrony: alternative work schedules, jetlag, altered light exposure and electronic media \\ Shift work}

In industrialized society, approximately $20 \%$ of the population works beyond the normative day shift, in various schedules of shift work. ${ }^{12,27-29}$ Ample research has been done on the effects of shift work on sleep and related health and performance outcomes. ${ }^{28,30-35}$

The characteristics of sleep in shift workers have been reviewed by Åkerstedt. ${ }^{33}$ Night shift workers exhibit shortened subsequent daytime sleep, more objective and subjective measures of sleepiness, lasting for several days following the night shift, and are prone to falling asleep during the shift, particularly towards the early morning hours. Morning shift workers experience curtailed sleep due to early rise times and subsequent daytime sleepiness. Taken together, reduced sleep and excessive sleepiness in shift workers have been implicated as mediators of impaired safety, productivity, performance and health. . $^{28,29,31,36,37}$

To understand why shift workers experience reduced sleep time and sleepiness, it is necessary to describe the human circadian timing system. Physiological and behavioral processes, including the secretion of hormones, the sleep/wake schedule and the performance of mental activities, are known to oscillate in circadian (about 24 hours) cycles that are controlled by the biological clock, located in the suprachiasmatic nucleus of the hypothalamus. ${ }^{12,38}$ Under normal conditions, circadian rhythms are entrained to the environmental light-dark cycle and are synchronized with it. Thus, time-of-day effects demonstrate increased sleep propensity and reduced alertness and performance capacity in the early morning hours, corresponding to the minimum in core body temperature, the peak of melatonin secretion and the timing of the habitual sleep phase. ${ }^{39,40}$ Changes in the timing of sleep and wake periods create circadian desynchrony. Shift workers on night or rotating shifts are required to remain awake during periods of increased sleep propensity; and the timing of their sleep phase is shifted to the daytime hours, when rhythms of performance, alertness and core body temperature are on the rise. ${ }^{12,39,40}$ Daytime sleep is shorter, ensuing in partial sleep deprivation and sleepiness. Such chronic exposure to circadian desynchrony entails serious consequences, by compromising safety, productivity and health. ${ }^{28,37,41}$ Some of the immediate consequences of shift work include increased risks for human error, accidents and injuries. ${ }^{31,37,42}$

Shift Work Sleep Disorder (SWSD) has been defined by The International Classification of Sleep Disorders, 2nd edition ${ }^{43}$ as the presence of insomnia and/or daytime sleepiness associated with shift work. In a study on its prevalence and characteristics, the true prevalence of SWSD was $14 \%$ in night shift workers and $8 \%$ in rotating shift workers, after removing the percentage of insomnia and excessive sleepiness found in day workers. ${ }^{36}$ Those with SWSD had higher rates of ulcers and depression, missed more work days and more family/social events, and had higher scores of neuroticism and more sleepiness-related accidents, than their shift work counterparts who did not have SWSD. For most of these outcomes, workers with SWSD had increased morbidity in comparison to their day work counterparts with the same symptoms (ie, insomnia and daytime sleepiness without shiftwork). These findings demonstrate the additive effects of symptoms of poor sleep (insomnia, excessive sleepiness) and work schedule (circadian desynchrony) on serious health and functional outcomes. ${ }^{12,36}$

Cross sectional and longitudinal investigations indicate that shift workers are at an increased risk for developing health problems, including gastrointestinal and cardiovascular diseases, diabetes and metabolic disorders, breast and colon cancers. ${ }^{12,34,41}$ Investigations on the mechanisms underlying these relationships suggest that sleep deprivation and circadian desynchrony are involved in changes in neuroendocrine function, reduced capacity of the immune system, metabolic disturbances and tumor growth. ${ }^{34,41,44,45}$ Exposure to light at night, leading to melatonin suppression, has also been implicated as an underlying mechanism (see below).

\section{Flexible work systems}

In addition to shift work, flexible work systems in which workers are not confined to traditional work hours have become increasingly prevalent. ${ }^{27,28}$ Flexibilization is a relatively new concept in organizational management, and is linked to trends in globalized economy. ${ }^{46}$ Such nonstandard work schedules are highly variable among organizations, and may include working evenings, weekends, split shifts, on call hours or compressed work weeks. ${ }^{27,30}$ Though seemingly an attractive approach for allowing workers to tailor their work 
schedule to their individual needs ${ }^{47}$ flexible work schedules may have a negative impact on workers' health.

In a study comparing traditional and nontraditional work schedules, scores of physical health, mental wellbeing and sleep quality were consistently higher for the traditional schedule workers..$^{30}$ Specifically, sleep quality was significantly lower in those working irregular shifts and compressed work weeks (10-12 hour 3-4 weekly shifts). Pending further investigation, the effects of flexible work systems on sleep and health may depend on workers' degree of flexibility; ie, increasing workers' control and choice of their work schedules may have beneficial effects on their sleep, health and overall wellbeing; whereas organizational enforced work schedules have a more negative impact on workers' overall health. ${ }^{48}$

\section{Jet lag}

Jet lag is another circadian rhythm disorder which has emerged vis a vis the widespread popularity of transmeridian travel in recent decades. ${ }^{14}$ Circadian desynchrony between the sleep-wake schedule and other endogenous circadian rhythms with the environmental light-dark cycle creates symptoms of jet lag, including daytime sleepiness, difficulty falling asleep during eastward flights, early morning awakenings on westward flights, impaired alertness and performance as well as gastrointestinal problems and loss of appetite. ${ }^{12}$

The circadian timing system is able to readjust to new environmental time cues. On average, the adaptation rate is an hour a day, so that, depending on the number of time zones crossed and individual differences, travelers can expect their circadian system to adapt to the new time zone, given that they remain at their destination for a sufficient amount of time. ${ }^{12}$ However, when transmeridian travel is ongoing, such as in the case of aircrew cabin workers, chronic jet lag is associated with reduced cognitive capacities and higher levels of cortisol. ${ }^{49}$ Furthermore, chronic jet lag simulated in laboratory mice is associated with dysregulation of the immune system, that is mediated by circadian desynchrony but not by sleep loss. ${ }^{50}$ Future investigations may further elaborate on the long term effects of jet lag on sleep, performance and health.

Both jet lag and shift work represent disorders in which a circadian system functions properly under normal conditions, but cannot adjust under voluntary or imposed phase shifts. For evaluation and management purposes, they are collectively referred to as circadian rhythm sleep disorders (CRSDs) ${ }^{51}$ (see treatment section).

\section{Altered exposure to light}

Light exposure plays a strong role in the circadian timing system. The resetting effects of light on the human circadian system have been described, demonstrating that timed exposure to bright light can create both a delay and an advance in the timing of circadian rhythms..$^{52,53}$ Bright light during the night has also been found to have immediate effects on physiological and behavioral measures. ${ }^{54} \mathrm{In}$ comparison to dim light, bright light exposure decreased sleepiness, increased alertness, improved performance on behavioral tasks and attenuated the nightly drop in core body temperature. Taken together, these findings demonstrate that bright light may be used therapeutically to reset the circadian system, eg, in the case of jet lag; and to exert immediate effects of enhanced alertness in the context of nighttime shift work.

Indeed, light exposure has been shown to be a potent treatment for various circadian rhythm disorders (see section on treatment). However, accumulating lines of evidence point to the negative effects of exposure to light during the nighttime hours. Such exposure has become extremely common in various contexts in the modern world.

One line of evidence refers to nighttime light exposure as a risk factor for breast and prostate cancer. ${ }^{55-57}$ Epidemiological studies have shown an increased risk for breast cancer in women exposed to nighttime light in the home environment as well as in nightshift workers. ${ }^{57,58}$ Based on animal studies and human epidemiological studies, the light at night (LAN) theory implicates that circadian disruption and melatonin suppression by nighttime light exposure are the underlying mechanisms leading to tumor growth. ${ }^{59,60}$

Another line of evidence of the harmful effects of mistimed light exposure refers to a new concept, termed asynchronization, in children and adolescents.$^{61}$ This concept attempts to explain the high prevalence of insomnia and daytime sleepiness in children. Similar to the LAN theory, sleep is disrupted due to late night light exposure, causing circadian desynchrony and melatonin suppression. Also, lack of early morning light exposure prevents normal circadian entrainment to the environmental light/dark cycle. Future prospective intervention studies designed to enhance circadian entrainment in young individuals may provide support for the asynchronization model.

Finally, daylight savings time (DST), yet another relatively novel feature of modern society, has received little attention in the scientific literature. During the DST transitions in spring and autumn, social, but not environmental time cues shift abruptly, creating a one hour advance (in spring) and a 
one hour delay (in autumn) of the timing of dawn relative to the shifted social norms. In a study using pooled data of several western European countries, which aimed to assess the effects of DST on physiological and behavioral entrainment to the environment, investigators have found that sleep time adjusts to the seasonal progression of dawn during standard time, but not during DST.62 Furthermore, when comparing morning and evening chronotypes, they found that sleep and activity rhythms fail to adjust to DST, particularly in evening chronotypes. Further investigations may assess the consequences of this failure to entrain during DST on measures of functioning and health.

\section{Electronic media exposure}

Associations between sleep patterns and electronic media exposure have been reported extensively in children and adolescents ${ }^{15,17,63-68}$ as well as in adults. ${ }^{66,69}$ Overall, electronic media exposure in children and adolescents was most consistently associated with later bedtime and shorter sleep duration, and the presence of a media device in the bedroom was associated with increased exposure, later bedtime and shorter sleep. ${ }^{16,17,63}$ In a 1-year prospective study of young men and women, looking at the psychological effects of exposure to various types of information and communication technologies (ICT), increased internet surfing for women, and increased cell phone calls and SMS messages for men, were found to increase the risk of developing sleep disturbances. ${ }^{69}$

Attempts to conceptualize the underpinnings of these associations remain speculative. Van den Bulck ${ }^{16,70}$ has referred to electronic media exposure as an unstructured and boundless leisure activity with no clear endpoints, unlike other hobbies or sports activities. Shochat and associates ${ }^{17}$ have suggested that a media device in the bedroom may indicate high availability of the device and low parental control, both leading to increased exposure. It has also been suggested that electronic media exposure may have alerting effects, ${ }^{17,70}$ possibly due to the suppression of melatonin by the bright light emanating from electronic screens ${ }^{71}$ as well as due to their engaging and exciting content.

Cain and Gradisar ${ }^{68}$ have suggested a model designed to demonstrate putative factors mediating the effects of electronic media on sleep in young individuals. Based on this model, background variables such as age, socioeconomic status and parental control may impact the intensity of electronic media use, including the presence or absence of a media device in the bedroom. In turn, proposed mechanisms that lead to sleep disruption include a physiological delay in the circadian sleep/wake rhythm, as well as physiological, mental and cognitive excitement and arousal. Sleep disruption subsequently leads to impaired daytime functioning. Future lines of investigation may further validate these relationships via experimental and longitudinal designs.

\section{Behavioral patterns and countermeasures of sleep disorders and sleepiness: weight gain, physical activity and use of substances \\ Weight gain}

Levels of obesity and overweight have dramatically risen in developed and developing societies, reaching pandemic proportions in children and adults alike. ${ }^{72,73}$ In the past two decades the average level of obesity in OECD countries has risen by 8 percent. $^{74}$ In the United States in 2004, 17\% of the child and adolescent population was overweight and one third of the adult population was obese. ${ }^{75}$ These rates were significantly increased in children and adolescents and in adult males (but not women) compared to rates from 1999. The public health impact of obesity has been reviewed, linking obesity with type 2 diabetes, cancers, cardiovascular diseases, musculoskeletal disorders, respiratory disorders including sleep apnea, and all-cause mortality. ${ }^{76}$

Environmental and behavioral changes have been implicated as the major factors responsible for weight gain, ${ }^{72}$ particularly changes in dietary habits (ie, high fat, energy dense diets), reduced physical activities corresponding to increased sedentary activities, eg, television exposure, ${ }^{77}$ as well as decreased duration of sleep..$^{72,77-84}$ Studies have investigated sleep as both a cause and a consequence of weight gain.

As part of a cross-sectional survey on health and nutrition in European teens, shorter sleep was associated with higher measures of obesity, including body mass index, waist circumference and body fat percentage. ${ }^{81}$ Short sleepers reported more sedentary time, watched more television and maintained a less nutritional diet compared to adequate sleepers ( $\geq 8$ hours of sleep per night). In a six year prospective study, a comparison of adiposity measures was made on adults who were short sleepers at baseline ( $\leq 6$ hours per night), between those who remained short sleepers and those who increased their sleep to 7-8 hours per night. These groups were also compared to long (7-8 hours) sleepers both at baseline and at 6-year follow up. Both short sleeper groups had comparable adiposity measures at baseline, whereas at follow up, the short sleepers group increased body mass index and body mass, compared to the increased sleepers group, who showed similar measures to the long sleepers. ${ }^{84}$ 
Possible mechanisms underlying the relationship between short sleep duration and obesity have been suggested. Studies have demonstrated that regulation of the hormones leptin and ghrelin, signaling satiety and appetite respectively, is disrupted due to sleep loss, resulting in increased hunger and appetite. ${ }^{83,85-87}$ Furthermore, it has been shown that during television viewing, metabolic rate is low $^{88}$ and metabolic risk is increased. ${ }^{89}$ It has been suggested that increased television viewing leads to reduced sleep duration, which in turn leads to increased hunger and decreased metabolic rate, ultimately resulting in overweight and obesity. ${ }^{78}$ However, in a critical review, Marshall and associates ${ }^{90}$ have concluded that there is insufficient and conflicting evidence regarding short sleep duration as a risk factor for obesity, and warned that advocacy of such a public health message is premature. Clearly, additional experimental and longitudinal studies are needed to determine possible causal pathways between these variables.

Conversly, obesity has been associated with an increased risk for sleep disordered breathing (SDB), both in children and adults. ${ }^{91-95}$ Tauman and Gozal ${ }^{91}$ have reviewed the evidence that obesity is a risk factor for obstructive sleep apnea (OSA) in children, and have suggested that in obese individuals low bioavailability of leptin, an important regulatory hormone of ventilatory mechanisms, may be a possible mediator. The authors further suggest that obstructive sleep apnea may in turn contribute to the strong links between obesity and comorbidities such as cardiovascular disease and the metabolic syndrome, possibly by amplifying inflammatory processes.

Nevertheless, obesity may not unequivocally be considered as a risk factor for SDB in young individuals. ${ }^{96,97}$ Kohler and van den Heuve $1{ }^{97}$ have suggested that developmental stages as well as ethnic differences and their underlying anatomic and genetic predispositions are likely to be important moderators in this relationship. It may be concluded, that while obesity and SDB have many common clinical features and likely interact reciprocally, much investigation is needed to further understand the underpinnings of their relationship..$^{96,97}$

Finally, it is noteworthy that studies have found an increased prevalence of insomnia in adults with SDB. ${ }^{98,99} \mathrm{Of}$ a random sample of patients diagnosed with SDB, Krakow and associates ${ }^{99}$ found that $50 \%$ also had clinically significant signs of insomnia, and that those patients with both SDB and insomnia had more medical and psychiatric disorders and consumed more sedatives and psychotropic medications compared to SDB patients without insomnia. Whereas causal relationships between SDB and insomnia are at present speculative, it may be assumed that SDB contributes to the development of insomnia via sleep fragmentation. ${ }^{98}$ Inasmuch as rates of SDB have increased, in part due to the increase in weight gain, ${ }^{91,94}$ SDB may be considered as a lifestyle-related medical condition that is associated with insomnia. Whether weight gain itself is also associated with insomnia is yet to be determined.

\section{Physical activity}

Epidemiological studies have established that levels of physical activity (PA) are low in US adolescents and adults, and that PA declines and inactivity increases between adolescence and young adulthood. ${ }^{100,101}$ Yet investigations focusing on the relationship between sleep and physical activity, exercise, and inactivity in the community are few. Different PA protocols and measures, as well as individual differences in age, gender, and fitness obscure the ability to support the underlying assumption that exercise promotes sleep. ${ }^{102}$ In patients with sleep apnea, a tendency towards an inverse relationship between PA and the respiratory disturbance index (RDI) was demonstrated, ie, higher PA was associated with a lower RDI. ${ }^{103}$ Findings from the Sleep Heart Health Study (SHHS) ${ }^{104}$ have shown that vigorous PA performed at least 3 hours weekly was associated with a reduced risk for SDB, particularly in obese men. Clinical prospective protocols are warranted to assess the feasibility and efficacy of applying PA in intervention programs for SDB. In older adults, PA has been found to be a protective factor for incident and persistent late life insomnia. ${ }^{105}$ Yet in a study assessing sleep and PA using actigraphic (activity monitor) measures in 8-year-old children, a bidirectional inverse relationship was found, showing that increased PA during the day was associated with lower subsequent nighttime sleep quality, and improved nighttime sleep measures were related to lower levels of PA on the following day. ${ }^{106}$ Clearly, further investigations must be done to identify developmental changes and to clarify the underlying mechanisms in the relationship between PA and sleep.

\section{Caffeine, alcohol and other health risk substances}

In a recent nationally representative epidemiological study in high school students in the United States, insufficient sleep ( $<8$ hours/per night) was reported by over two thirds of the students. ${ }^{107}$ Strong associations were found between insufficient sleep and several prevalent health risk behaviors, including current use of alcohol (46\%), smoking cigarettes (21\%) and marijuana (21\%), being sexually active 
(36\%), being involved in a physical fight $(35 \%)$, low PA $(66 \%)$, increased sedentary activities ( $\mathrm{TV} \geq 3$ hours [36\%], computers $\geq 3$ hours [25\%], see section on electronic media above) and signs of depressed mood (28\%). Earlier epidemiologic studies have also reported that sleep problems and an evening tendency in adolescents were associated with the use of alcohol, caffeine, cigarettes, and illicit drugs. ${ }^{108,109}$ Psychiatric problems generally modified these associations, with the exception of illicit drugs and sleep problems, which were unrelated to psychiatric problems. ${ }^{108}$

Given the high prevalences of both insuffucient/disturbed sleep and the use of health-risk substances, it is imperative to understand the underlying mechanisms of these associations, in order to develop appropriate public health interventions. In this section, findings on relationships between sleep disturbances and caffeine, alcohol and cigarette smoking will be discussed, as these health risk substances have been the main focus of investigation in relation to sleep disturbances.

\section{Caffeine}

Caffeine is a widely consumed psychoactive substance. As an adenosine antagonist, caffeine has been shown to attenuate electroencephalographic markers associated with the decrease of homeostatic sleep pressure. ${ }^{110}$ Caffeine has been shown to combat sleepiness and to restore alertness and performance in experimental designs; however, habitual daily caffeine consumption has been related to sleep disruption and sleepiness. ${ }^{111}$ Evening consumption of caffeine has been shown to increase sleep latency and decrease sleep duration, sleep efficiency and stage 2 sleep in young and middle-aged adults. ${ }^{112}$

Caffeinated beverages have become increasingly popular among young individuals. Based on an epidemiologic study of over 7000 Icelandic 9th and 10th graders, 76\% reported daily consumption, ${ }^{19}$ as was found in the United States poll of the National Sleep Foundation. ${ }^{113}$ Such a high prevalence greatly exceeds the lifetime prevalence of alcohol (56\%) or nicotine use $(28 \%)$ in the adolescent population. ${ }^{19}$ Though seemingly benign, caffeine consumption was independantly associated with increased daytime sleepiness and decreased academic performance, and substantially contributed to the negative relationships between nicotine and alcohol use and academic performance. ${ }^{19}$

Increased nightly caffeine consumption has also been associated with increased multitasking of electronic media devices prior to bedtime in middle and high school students. ${ }^{15}$ Students who both multitasked and consumed caffeine were
$70 \%$ more likely to fall asleep at school, and $20 \%$ more likely to report difficulty falling asleep on school nights.

In a survey exploring patterns as well as reasons and expectations of caffeine consumption among adolescents, $95 \%$ of a high school sample consumed caffeine within the 2 weeks of the survey. ${ }^{18}$ Students reported drinking mostly caffeinated sodas, followed by coffee, with highest consumption rates in the evening hours. High caffeine consumers who drank both sodas and coffee reported more dependence issues, had higher expectations regarding caffeine as an energy enhancer and a substance that gets them through the day, and reported more daytime sleepiness compared to the lower caffeine consumers. Nevertheless, adolescents in this sample generally showed little concern with any of the effects of caffeine use, possibly indicating that they are simply unaware of these effects.

While most studies have focused on the effects of moderate levels of caffeine consumed in coffee and/or caffeinated soft drinks, few have focused on energy drinks, which are a fast growing segment of the beverage market and are particularly popular among youth. ${ }^{114}$ The content of caffeine in these drinks ranges between 50-500 mg per can or bottle. Findings from the Icelandic study showed that $38 \%$ of the daily caffeine consumers drank energy drinks, following $66 \%$ who were cola drinkers. ${ }^{19}$

The acute and long term effects of energy drinks on health and performance are largely unknown; ${ }^{114}$ however, reports of caffeine intoxication suggest that these drinks may increase problems of caffeine dependance and withdrawal as well as use of other drug substances. Longitudinal studies assessing the effects of energy drinks on sleep are warranted, taking into consideration not only differences in caffeine content and additional ingredients, but also looking at differences in drinking and sleeping patterns on weekdays versus weekends, as well as possible demographic mediating factors such as age, gender, socioeconomic status and culture.

\section{Alcohol}

The use of alcohol in young individuals has been shown to increase over time. In a recent study from the Netherlands comprised of two cohorts (1993, 2005-2008) and of 3 age groups (13-15, 16-17 and 18-21), the prevalence of alcohol initiation increased, particularly in the youngest age group (from 63\% in 1993 to $74 \%$ in 2005-2008). Quantities of alcohol consumption also increased significantly between cohorts. ${ }^{115}$

The effects of alcohol on sleep are well documented. Based on PSG recordings in young adults, evening 
consumption of a high alcohol dose (breath alcohol concentration [BrAC] 0.10) reduced sleep latency and efficiency and increased wake time throughout the night. ${ }^{116}$ Sleep consolidation was high during the first half of the night, and decreased during the second half. Subjective sleepiness increased, and sleep quality ratings decreased. These effects were more pronounced for women. Beyond its effects on sleep, alcohol created hangover and reduced performance on tasks requiring sustained attention and speed on the following morning. ${ }^{117}$

As alcohol consumption often begins in early adolescence, and as sleep disturbances are highly prevalent in this age group, Pieters and associates ${ }^{118}$ sought to investigate possible mediators of the relationship between the two. They found that puberty was related to alcohol use directly, but also indirectly, via sleep problems and delayed phase preference that typically begins in early adolescence. It was concluded that puberty-related changes in sleep regulation may underlie the vulnerability of young adolescents to alcohol consumption. In a prospective study of children of alcoholics, sleep problems in early childhood predicted substance use in adolescence, particularly in boys. ${ }^{119}$ Whether these finding generalize to children of parents free of substance abuse may be determined in future prospective investigations.

\section{Cigarette smoking}

Cigarette smoking has been recognized as a behavior that interferes with sleep. Laboratory and survey studies have reported that adult smokers experience more difficulty falling asleep and more sleep fragmentation than non smokers, probably due to the stimulant effects of nicotine. ${ }^{120-122}$ In a study assessing smoking patterns and sleep quality, night smokers had a higher prevalence of poor sleep and reported more sleep disturbances than non-night smokers. ${ }^{123}$ Sleep duration was considerably shorter in night smokers who had poor sleep, compared to poor sleepers who did not smoke at night. Furthermore, night smoking and sleep disturbances both increased the risk of smoking cessation failure.

In smokers compared to nonsmokers, a higher prevalence of sleep bruxism has been reported. ${ }^{124}$ However, no differences have been found for either restless legs syndrome (RLS) and periodic limb movements in sleep (PLMS), ${ }^{124}$ or respiratory disturbances in healthy individuals. ${ }^{125}$

Although general trends across cohorts demonstrate a substantial reduction in the prevalence of cigarette smoking and increased smoking cessation, adolescents and young adults constitute the most vulnerable age range for smoking initiation. ${ }^{126,127}$ In adolescents, cigarette smoking has been associated with an evening preference and with early puberty. ${ }^{109,128}$ In a survey on perceptions of sleep in high school adolescents, $6 \%$ of the entire sample reported that they smoke as a means to help them fall asleep. ${ }^{129}$ In a prospective 2 wave study of insomnia and risk taking behaviors, the presence of insomnia predicted smoking within each wave, but not longitudinally. ${ }^{130}$ Clearly, more prospective studies are needed to understand the direction of this relationship and how it may change developmentally.

\section{Treatment of lifestyle and technology related sleep disturbances}

The development of treatment strategies designed for specific lifestyle related sleep disturbances have largely focused on the treatment of circadian rhythm sleep disorders, ie, shift work and jet lag. Few interventions have been developed for other environmental and behavioral lifestyle factors affecting sleep, such as electronic media exposure, physical activity, weight gain and substance use. For standard guidelines on the diagnosis and treatment of sleep disorders, readers are referred to the International Classification of Sleep Disorders, 2nd edition. ${ }^{43}$

\section{Treatment of circadian rhythm sleep disorders (CRSD) and altered light exposure}

Shift work and jet lag are treated based on guidelines for the treatment of CRSD,${ }^{51}$ which include prescribed sleep scheduling, phase shifting with light exposure and/or melatonin (and its agonist) administration, and symptomatic treatments to combat insomnia and excessive sleepiness.

Prescribed sleep scheduling refers to changes in sleep and wake timing that are designed to optimize sleep quality during the sleep period and alertness during the wake period. "Chronotherapy" refers to treatment that is optimized by application based on oscillations of the circadian timing system. It was initially introduced to treat individuals with delayed sleep phase by gradual delay of sleep episodes until achieving a desired sleep phase. ${ }^{131}$ Chronotherapy and chronopharmacy have been under investigation for application in the treatment of cancers ${ }^{132}$ as well as hypertension and asthma. ${ }^{133,134}$ In shift workers, investigations assessing optimal shift schedules based on chronobiological principles have suggested that clockwise rotation is more beneficial to workers than counterclockwise rotation, in terms of adaptation, health and wellbeing. ${ }^{41,135}$ 
Another sleep scheduling strategy is planned napping either prior to or during the work shift, aimed to offset the immediate effects of sleepiness on performance during the nightshift. ${ }^{136,137}$ These and other studies have demonstrated that short naps of 20-40 minutes were sufficient to improve alertness and performance measures during the night.

The circadian resetting and immediate alerting effects of light exposure have been described (see section on altered exposure to light). Though well-established, the applicability of achieving the effects of light to counter nighttime sleepiness in shift workers has been hampered by investigations demonstrating that nighttime light exposure and its suppressant effect on melatonin production may be the cause of an increased risk of tumor growth in animal studies. ${ }^{138}$ However, investigational efforts to overcome this untoward effect, eg, by filtering low wavelength light, which suppresses melatonin, without compromising the positive effects of light on alertness and performance, ${ }^{139}$ may lead to revised guidelines for safe and efficient exposure to bright light during the night shift. Avoidance of early morning bright light on the ride home from work has also been found to be beneficial to allow a smoother transition to the morning sleep period. ${ }^{140}$ For jet lag, appropriately timed light exposure at the destination of travel has also been found to be beneficial. ${ }^{141}$ Westward travelers may benefit from evening light exposure and avoiding morning light exposure at their destination; while eastward travelers should avoid evening light and be exposed to morning light, in order to achieve an advanced sleep phase.

To improve sleep in CRSD, melatonin and its agonist as well as sleep medications are recommended prior to the desired sleep time. However, sedating medications should be used with caution when used during the day, as they compromise alertness, safety and performance. Conversely, wake-promoting agents, modafinil and armodafinil, have proven effective for increasing alertness and performance during shift work. ${ }^{141}$

Finally, maintenance of sleep hygiene practices, such as achieving an adequate amount of sleep, sleeping in a dark and quiet environment and controlling caffeine and alcohol consumption, are recommended for the treatment of insomnia related to $\mathrm{CRSD}$. ${ }^{12,51}$

\section{Behavioral lifestyle factors}

While intervention studies aimed to modify health related lifestyle behaviors (eg, weight gain, sedentary activity and substance use) have shown some positive outcomes, few have reported sleep as a major outcome.

Randomized clinical trials have demonstrated that weight reduction has a significant impact on OSA. ${ }^{142,143}$
In overweight individuals with mild OSA, a lifestyle intervention with a very low calorie diet significantly reduced body weight and apnea/hypopnea index (AHI), and improved related symptoms and measures of quality of life. ${ }^{143}$ Similar findings were found for overweight individuals with moderate to severe OSA. ${ }^{142}$ Improvements were maintained at the 1 year follow-up in both studies.

Exercise interventions have shown some benefits in sleep quality for clinical populations ${ }^{144,145}$ and postmenopausal women. ${ }^{146}$ Tai Chi, a traditional Chinese exercise of low to moderate intensity has shown positive benefits on sleep quality and daytime sleepiness in older adults. ${ }^{147,148}$ Aerobic exercise has been shown to decrease symptoms of sleep disordered breathing in overweight children. ${ }^{149}$

In a public health intervention aimed at enhancing multiple health behaviors in high school adolescents, ${ }^{150}$ positive outcomes included reductions in alcohol use and increases in fruit and vegetable consumption and participation in relaxation activities. Sleep measures, exercise, cigarette and marijuana use remained unchanged. Health education interventions specifically targeting adolescent sleep problems have shown that despite improvements in sleep knowledge and motivation, no behavioral changes in sleep practices were achieved. ${ }^{151,152}$ However, in a recent cognitive behavioral therapy (CBT) intervention on school-aged children, significant improvements were found in sleep measures such as sleep latency, sleep efficiency and wake time after sleep onset, and were maintained at follow-up..$^{153}$

In summary, interventions aimed at improving sleep disturbances that are related to specific behavioral lifestyle habits are only beginning to emerge. It is interesting to note that conversely, sleep extension has been recommended as an intervention to avoid weight gain and allow weight loss, particularly in young individuals, ${ }^{83,154,155}$ however, to date, outcome studies have yet to be reported.

\section{Future perspectives}

Despite ample evidence of the associations between lifestyle health behaviors and sleep quality, a comprehensive understanding of the causal relationships may be difficult to achieve. Lifestyle, technology and health behaviors including sleep are all intertwined and strongly embedded in the cultural and social environment. Prospective and longitudinal investigations following sleep patterns and related lifestyle behaviors are needed, to attempt to tease apart some of these variables and establish the temporal order of events. Such studies may also incorporate demographic, psychosocial and biological inter-individual differences, 
to develop mediating models and to establish possible underlying mechanisms.

The development of public health interventions targeting specific lifestyle behaviors associated with poor sleep, tailored for different age groups, are warranted. Electronic media exposure, eating, and physical activity habits in children; risk behaviors and appropriately timed light exposure in adolescents and young adults are some examples.

\section{Disclosure}

The author reports no conflicts of interest in this work.

\section{References}

1. Aserinsky E, Kleitman N. Regularly occurring periods of eye motility, and concomitant phenomena, during sleep. Science. 1953;118(3062):273-274.

2. Dement W, Kleitman N. Cyclic variations in EEG during sleep and their relation to eye movements, body motility, and dreaming. Electroencephalogr Clin Neurophysiol. 1957;9(4):673-690.

3. Ancoli-Israel S. "Sleep is not tangible" or what the Hebrew tradition has to say about sleep. Psychosom Med. 2001;63(5):778-787.

4. Kryger MH. Sleep apnea: From the needles of Dionysius to continuous positive airway pressure. Arch Intern Med. 1983;143(12):2301-2303.

5. Kryger MH. Fat, sleep, and Charles Dickens: Literary and medical contributions to the understanding of sleep apnea. Clin Chest Med. 1985;6(4):555-562.

6. Lavie P. Nothing new under the moon. historical accounts of sleep apnea syndrome. Arch Intern Med. 1984;144(10):2025-2028.

7. Lavie P. Who was the first to use the term Pickwickian in connection with sleepy patients? History of sleep apnoea syndrome. Sleep Med Rev. 2008;12(1):5-17.

8. Guilleminault C. Obstructive sleep apnea. The clinical syndrome and historical perspective. Med Clin North Am. 1985;69(6):1187-1203.

9. Stepanski EJ, Rybarczyk B. Emerging research on the treatment and etiology of secondary or comorbid insomnia. Sleep Med Rev. 2006;10(1):7-18.

10. Shochat T, Dagan E. Sleep disturbances in asymptomatic BRCA1/2 mutation carriers: women at high risk for breast-ovarian cancer. J Sleep Res. 2010;19(2):333-340.

11. Espie CA, Broomfield NM, MacMahon K, Macphee LM, Taylor LM. The attention-intention-effort pathway in the development of psychophysiologic insomnia: a theoretical review. Sleep Med Rev. 2006;10(4):215-245.

12. Rajaratnam SMW, Arendt J. Health in a 24-h society. The Lancet. 2001;358(9286):999-1005.

13. Scheer FAJL, Hilton MF, Mantzoros CS, Shea SA. Adverse metabolic and cardiovascular consequences of circadian misalignment. Proc Natl Acad Sci U S A. 2009;106(11):4453.

14. Waterhouse J, Reilly T, Atkinson G. Jet-lag. Lancet. 1997;350(9091):1611-1616.

15. Calamaro CJ, Mason T, Ratcliffe SJ. Adolescents living the 24/7 lifestyle: Effects of caffeine and technology on sleep duration and daytime functioning. Pediatrics. 2009;123(6):e1005-e1010.

16. Van den Bulck J. Television viewing, computer game playing, and internet use and self-reported time to bed and time out of bed in secondary-school children. Sleep. 2004;27(1):101-104.

17. Shochat T, Flint-Bretler O, Tzischinsky O. Sleep patterns, electronic media exposure and daytime sleep-related behaviours among Israeli adolescents. Acta Pcediatrica. 2010;99(9):1396-1400.

18. Bryant Ludden A, Wolfson AR. Understanding adolescent caffeine use: connecting use patterns with expectancies, reasons, and sleep. Health Educ Behav. 2010;37(3):330-342.
19. James JE, Kristjánsson ÁL, Sigfúsdóttir ID. Adolescent substance use, sleep, and academic achievement: evidence of harm due to caffeine. J Adolesc. 2011;34(4):665-673.

20. Shibley HL, Malcolm RJ, Veatch LM. Adolescents with insomnia and substance abuse: consequences and comorbidities. J Psychiatr Pract. 2008;14(3):146-153.

21. Stein MD, Friedmann PD. Disturbed sleep and its relationship to alcohol use. Subst Abus. 2005;26(1):1-13.

22. Obermeyer WH, Benca RM. Effects of drugs on sleep. Otolaryngol Clin North Am. 1999;32(2):289-302.

23. Jaehne A, Loessl B, Bárkai Z, Riemann D, Hornyak M. Effects of nicotine on sleep during consumption, withdrawal and replacement therapy. Sleep Med Rev. 2009;13(5):363-377.

24. Chaput JP, Sjödin AM, Astrup A, Després JP, Bouchard C, Tremblay A. Risk factors for adult overweight and obesity: the importance of looking beyond the 'big two'. Obes Facts. 2010;3(5):320-327.

25. Mozaffarian D, Hao T, Rimm EB, Willett WC, Hu FB. Changes in diet and lifestyle and long-term weight gain in women and men. $N$ Engl $J$ Med. 2011;364(25):2392-2404.

26. Peppard PE, Young T, Palta M, Dempsey J, Skatrud J. Longitudinal study of moderate weight change and sleep-disordered breathing. JAMA. 2000;284(23):3015-3021.

27. Beers TM. Flexible schedules and shift work: Replacing the 9-to-5 workday? Monthly Labor Rev. 2000;123:33-40.

28. Costa G. Shift work and occupational medicine: An overview. Occup Med (Lond). 2003;53(2):83-88.

29. Gordon NP, Cleary PD, Parker CE, Czeisler CA. The prevalence and health impact of shiftwork. Am J Public Health. 1986;76(10): $1225-1228$.

30. Martens M, Nijhuis F, Van Boxtel M, Knottnerus J. Flexible work schedules and mental and physical health. A study of a working population with non-traditional working hours. J Organ Behav. 1999;20(1):35-46.

31. Smith L, Folkard S, Poole C. Increased injuries on night shift. Lancet. 1994;344(8930):1137-1139.

32. Van Dongen HPA. Shift work and inter-individual differences in sleep and sleepiness. Chronobiol Int. 2006;23(6):1139-1147.

33. Åkerstedt T. Shift work and disturbed sleep/wakefulness. Occup Med. 2003;53(2):89-94.

34. Knutsson A. Health disorders of shift workers. Occup Med. 2003;53(2): 103-108.

35. Åkerstedt T, Wright KP Jr. Sleep loss and fatigue in shift work and shift work disorder. Sleep Med Clin. 2009;4(2):257-271.

36. Drake CL, Roehrs T, Richardson G, Walsh JK, Roth T. Shift work sleep disorder: prevalence and consequences beyond that of symptomatic day workers. Sleep. 2004;27(8):1453-1462.

37. Folkard S, Tucker P. Shift work, safety and productivity. Occup Med. 2003;53(2):95-101.

38. Klein DC, Moore RY, Reppert SM. Suprachiasmatic Nucleus: The mind's Clock. New York: Oxford University Press; 1991.

39. Dijk DJ, Duffy JF, Riel E, Shanahan TL, Czeisler CA. Ageing and the circadian and homeostatic regulation of human sleep during forced desynchrony of rest, melatonin and temperature rhythms. $J$ Physiol. 1999;516(Pt 2):611-627.

40. Johnson M, Duffy J, Dijk D, Ronda J, Dyal C, Czeisler C. Short-term memory, alertness and performance: a reappraisal of their relationship to body temperature. J Sleep Res. 1992;1(1):24-29.

41. Haus E, Smolensky M. Biological clocks and shift work: circadian dysregulation and potential long-term effects. Cancer Causes Control. 2006;17(4):489-500.

42. Smith R, Kushida C. Risk of fatal occupational injury by time of day. Sleep. 2000;23 Suppl 2:A110-A111.

43. American Academy of Sleep Medicine. The International Classification of Sleep Disorders: Diagnostic and Coding Manual. 2nd ed. Westchester, IL: American Academy of Sleep Medicine; 2005.

44. Haus E, Smolensky MH. Biologic rhythms in the immune system. Chronobiol Int. 1999;16(5):581-622. 
45. Boggild H, Knutsson A. Shift work, risk factors and cardiovascular disease. Scand J Work Environ Health. 1999;25(2):85-99.

46. Oechsler W. Workplace and workforce $2000+$-the future of our work environment. Int Arch Occup Environ Health. 2000; 73 Suppl:S28-S32.

47. Hall DT, Parker VA. The role of workplace flexibility in managing diversity. Organ Dyn. 1993;22(1):5-18.

48. Joyce K, Pabayo R, Critchley JA, Bambra C. Flexible working conditions and their effects on employee health and wellbeing. Cochrane Database Syst Rev. 2010;2:CD008009.

49. Cho K, Ennaceur A, Cole JC, Suh CK. Chronic jet lag produces cognitive deficits. $J$ Neurosci. 2000;20(6):RC66.

50. Castanon-Cervantes O, Wu M, Ehlen JC, et al. Dysregulation of inflammatory responses by chronic circadian disruption. J Immunol. 2010;185(10):5796-5805.

51. Sack RL, Auckley D, Auger RR, et al. Circadian rhythm sleep disorders: Part I, basic principles, shift work and jet lag Disorders. An American Academy of Sleep Medicine review. Sleep. 2007;30(11):1460-1483.

52. Czeisler CA, Allan JS, Strogatz SH, et al. Bright light resets the human circadian pacemaker independent of the timing of the sleep-wake cycle. Science. 1986;233(4764):667-671.

53. Minors DS, Waterhouse JM, Wirz-Justice A. A human phase-response curve to light. Neurosci Lett. 1991;133(1):36-40.

54. Badia P, Myers B, Boecker M, Culpepper J, Harsh J. Bright light effects on body temperature, alertness, EEG and behavior. Physiol Behav. 1991;50(3):583-588.

55. Reiter RJ, Tan DX, Erren TC, Fuentes-Broto L, Paredes SD. Lightmediated perturbations of circadian timing and cancer risk: a mechanistic analysis. Integr Cancer Ther. 2009;8(4):354-360.

56. Stevens RG. Working against our endogenous circadian clock: Breast cancer and electric lighting in the modern world. Mutat Res. 2009;680(1-2):106-108.

57. Hansen J, Stevens RG. Case-control study of shift-work and breast cancer risk in Danish nurses: Impact of shift systems. Eur J Cancer. 2011. doi:10.1016/j.ejca.2011.07.005

58. Kloog I, Stevens RG, Haim A, Portnov BA. Nighttime light level codistributes with breast cancer incidence worldwide. Cancer Causes Control. 2010;21(12):2059-2068.

59. Kantermann T, Roenneberg T. Is light-at-night a health risk factor or a health risk predictor? Chronobiol Int. 2009;26(6):1069-1074.

60. Reiter RJ, Tan DX, Korkmaz A, et al. Light at night, chronodisruption, melatonin suppression, and cancer risk: A review. Crit Rev Oncog. 2007;13(4):303-328.

61. Kohyama J. Sleep health and asynchronization. Brain and Development. 2011;33(3):252-259.

62. Kantermann T, Juda M, Merrow M, Roenneberg T. The human circadian clock's seasonal adjustment is disrupted by daylight saving time. Curr Biol. 2007;17(22):1996-2000.

63. Owens J, Maxim R, McGuinn M, Nobile C, Msall M, Alario A. Television-viewing habits and sleep disturbance in school children. Pediatrics. 1999;104(3):e27.

64. Van den Bulck J. Television viewing, computer game playing, and internet use and self-reported time to bed and time out of bed in secondary-school children. Sleep. 2004;27(1):101-104.

65. Van den Bulck J. Adolescent use of mobile phones for calling and for sending text messages after lights out: Results from a prospective cohort study with a one-year follow-up. Sleep. 2007;30(9): $1220-1223$.

66. Suganuma N, Kikuchi T, Yanagi K, et al. Using electronic media before sleep can curtail sleep time and result in self-perceived insufficient sleep. Sleep Biol Rhythms. 2007;5(3):204-214.

67. Li S, Jin X, Wu S, Jiang F, Yan C, Shen X. The impact of media use on sleep patterns and sleep disorders among school-aged children in china. Sleep. 2007;30(3):361-367.

68. Cain N, Gradisar M. Electronic media use and sleep in schoolaged children and adolescents: A review. Sleep Med. 2010;11(8): 735-742.
69. Thomée S, Eklof M, Gustafsson E, Nilsson R, Hagberg M. Prevalence of perceived stress, symptoms of depression and sleep disturbances in relation to information and communication technology (ICT) use among young adults-an explorative prospective study. Comput Hum Behav. 2007;23(3):1300-1321.

70. Van den Bulck J. The effects of media on sleep. Adolesc Med State Art Rev. 2010;21(3):418-429, vii.

71. Higuchi S, Motohashi Y, Liu Y, Ahara M, Kaneko Y. Effects of VDT tasks with a bright display at night on melatonin, core temperature, heart rate, and sleepiness. J Appl Physiol. 2003;94(5):1773-1776.

72. World Health Organization. Obesity: Preventing and Managing the Global Epidemic. World Health Organization; 2000. Available from: http://www. who.int/nutrition/publications/obesity/WHO_TRS_894/en/.

73. Deckelbaum RJ, Williams CL. Childhood obesity: The health issue Obes Res. 2001;9 Suppl 4:239S-243S.

74. Bleich S, Cutler DM, Murray C, Adams A. Why is the Developed World Obese? 2007. National Bureau of Economic Research (NBER) Working Paper Series, No 12954. Available from: http://www.nber.org/papers/ w12954

75. Ogden CL, Carroll MD, Curtin LR, McDowell MA, Tabak CJ, Flegal KM. Prevalence of overweight and obesity in the United States, 1999-2004. JAMA. 2006;295(13):1549-1555.

76. Visscher TLS, Seidell JC. The public health impact of obesity. Annu Rev Public Health. 2001;22:355-375.

77. Gortmaker SL, Must A, Sobol AM, Peterson K, Colditz GA, Dietz WH. Television viewing as a cause of increasing obesity among children in the United States, 1986-1990. Arch Pediatr Adolesc Med. 1996;150(4):356-362.

78. Wells JC, Hallal PC, Reichert FF, Menezes AM, Araujo CL, Victora CG. Sleep patterns and television viewing in relation to obesity and blood pressure: Evidence from an adolescent Brazilian birth cohort. Int JObes. 2008;32(7):1042-1049.

79. Patel SR, Hu FB. Short sleep duration and weight gain: A systematic review. Obesity (Silver Spring). 2008;16(3):643-653.

80. Van Cauter E, Knutson KL. Sleep and the epidemic of obesity in children and adults. Eur J Endocrinol. 2008;159 Suppl 1:S59-S66.

81. Garaulet M, Ortega F, Ruiz J, et al. Short sleep duration is associated with increased obesity markers in European adolescents: effect of physical activity and dietary habits. The HELENA study. Int $J$ Obe (Lond). 2011;35(10):1308-1317.

82. Chaput JP, Després JP, Bouchard C, Tremblay A. Short sleep duration is associated with reduced leptin levels and increased adiposity: results from the Québec family study. Obesity (Silver Spring). 2007;15(1):253-261.

83. Leproult R, Van Cauter E. Role of sleep and sleep loss in hormonal release and metabolism. Endocr Dev. 2010;17:11-21.

84. Chaput J, Després J, Bouchard C, Tremblay A. Longer sleep duration associates with lower adiposity gain in adult short sleepers. Int $J$ Obes (Lond). 2011. doi: 10.1038/ijo.2011.110 [Epub ahead of print.]

85. Spiegel K, Leproult R, Van Cauter E. Impact of sleep debt on metabolic and endocrine function. Lancet. 1999;354(9188):1435-1439.

86. Spiegel K, Leproult R, L'Hermite-Balériaux M, Copinschi G, Penev PD, Van Cauter E. Leptin levels are dependent on sleep duration: Relationships with sympathovagal balance, carbohydrate regulation, cortisol, and thyrotropin. J Clin Endocrinol Metab. 2004;89(11):5762-5771.

87. Taheri S, Lin L, Austin D, Young T, Mignot E. Short sleep duration is associated with reduced leptin, elevated ghrelin, and increased body mass index. PLoS Med. 2004;1(3):e62.

88. Klesges RC, Shelton ML, Klesges LM. Effects of television on metabolic rate: Potential implications for childhood obesity. Pediatrics. 1993;91(2):281-286.

89. Ekelund U, Brage S, Froberg K, et al. TV viewing and physical activity are independently associated with metabolic risk in children: the European Youth Heart Study. PLoS Medicine. 2006;3(12):e488.

90. Marshall NS, Glozier N, Grunstein RR. Is sleep duration related to obesity? A critical review of the epidemiological evidence. Sleep Med Rev. 2008;12(4):289-298. 
91. Tauman R, Gozal D. Obesity and obstructive sleep apnea in children. Paediatr Respir Rev. 2006;7(4):247-259.

92. Shah N, Roux F. The relationship of obesity and obstructive sleep apnea. Clin Chest Med. 2009;30(3):455-465.

93. Verhulst SL, Van Gaal L, De Backer W, Desager K. The prevalence, anatomical correlates and treatment of sleep-disordered breathing in obese children and adolescents. Sleep Med Rev. 2008;12(5):339-346.

94. Young T, Peppard PE, Taheri S. Excess weight and sleep-disordered breathing. J Appl Physiol. 2005;99(4):1592-1599.

95. Young T, Shahar E, Nieto FJ, et al. Predictors of sleep-disordered breathing in community-dwelling adults: the Sleep Heart Health Study. Arch Intern Med. 2002;162(8):893-900.

96. Spruyt K, Gozal D. Mr. Pickwick and his child went on a field trip and returned almost empty handed..... what we do not know and imperatively need to learn about obesity and breathing during sleep in children! Sleep Med Rev. 2008;12(5):335-338.

97. Kohler MJ, van den Heuvel CJ. Is there a clear link between overweight/obesity and sleep disordered breathing in children? Sleep Med Rev. 2008;12(5):347-361.

98. Lavie P. Insomnia and sleep-disordered breathing. Sleep Med. 2007; 8 Suppl 4:S21-S25.

99. Krakow B, Melendrez D, Ferreira E, et al. Prevalence of insomnia symptoms in patients with sleep-disordered breathing. Chest. 2001;120(6): 1923-1929.

100. Jones AD, Ainsworth BE, Croft JB, Macera CA, Lloyd EE, Yusuf HR. Moderate leisure-time physical activity: Who is meeting the public health recommendations? A national cross-sectional study. Arch Fam Med. 1998;7(3):285-289.

101. Gordon-Larsen P, Nelson MC, Popkin BM. Longitudinal physical activity and sedentary behavior trends: adolescence to adulthood. $\mathrm{Am}$ J Prev Med. 2004;27(4):277-283.

102. Driver HS, Taylor SR. Exercise and sleep. Sleep Med Rev. 2000;4(4):387-402.

103. Hong S, Dimsdale JE. Physical activity and perception of energy and fatigue in obstructive sleep apnea. Med Sci Sports Exerc. 2003;35(7):1088-1092.

104. Quan SF, O'Connor GT, Quan JS, et al. Association of physical activity with sleep-disordered breathing. Sleep Breath. 2007;11(3):149-157.

105. Morgan K. Daytime activity and risk factors for late-life insomnia. J Sleep Res. 2003;12(3):231-238.

106. Pesonen AK, Sjöstén NM, Matthews KA, et al. Temporal associations between daytime physical activity and sleep in children. PLoS One. 2011;6(8):e22958.

107. McKnight-Eily LR, Eaton DK, Lowry R, Croft JB, PresleyCantrell L, Perry GS. Relationships between hours of sleep and healthrisk behaviors in US adolescent students. Prev Med. 2011;53(4-5): 271-273.

108. Johnson EO, Breslau N. Sleep problems and substance use in adolescence. Drug Alcohol Depend. 2001;64(1):1-7.

109. Giannotti F, Cortesi F, Sebastiani T, Ottaviano S. Circadian preference, sleep and daytime behaviour in adolescence. J Sleep Res. 2002;11(3):191-199.

110. Landolt HP, Retey JV, Tonz K, et al. Caffeine attenuates waking and sleep electroencephalographic markers of sleep homeostasis in humans. Neuropsychopharmacology. 2004;29(10):1933-1939.

111. Roehrs T, Roth T. Caffeine: sleep and daytime sleepiness. Sleep Med Rev. 2008;12(2):153-162.

112. Drapeau C, Hamel-Hebert I, Robillard RÉB, Selmaoui B, Filipini D, Carrier J. Challenging sleep in aging: the effects of $200 \mathrm{mg}$ of caffeine during the evening in young and middle-aged moderate caffeine consumers. J Sleep Res. 2006;15(2):133-141.

113. National Sleep Foundation (NSF) 2006 Sleep in America poll: Summary of findings. 2006. Washington, DC: National Sleep Foundation.

114. Reissig CJ, Strain EC, Griffiths RR. Caffeinated energy drinks - a growing problem. Drug Alcohol Depend. 2009;99(1-3):1-10.
115. Geels LM, Bartels M, van Beijsterveldt TCEM, et al. Trends in adolescent alcohol use: effects of age, sex and cohort on prevalence and heritability. Addiction. 2011. doi: 10.1111/j.1360-0443.2011.03612.x. [Epub ahead of print.]

116. Arnedt JT, Rohsenow DJ, Almeida AB, et al. Sleep following alcohol intoxication in healthy, young adults: effects of sex and family history of alcoholism. Alcohol Clin Exp Res. 2011;35(5):870-878.

117. Rohsenow DJ, Howland J, Arnedt JT, et al. Intoxication with bourbon versus vodka: Effects on hangover, sleep, and next-day neurocognitive performance in young adults. Alcohol Clin Exp Res. 2010;34(3):509-518.

118. Pieters S, Van Der Vorst H, Burk WJ, Wiers RW, Engels RCME. Puberty-dependent sleep regulation and alcohol use in early adolescents. Alcohol Clin Exp Res. 2010;34(9):1512-1518.

119. Wong MM, Brower KJ, Zucker RA. Childhood sleep problems, early onset of substance use and behavioral problems in adolescence. Sleep Med. 2009;10(7):787-796.

120. Wetter DW, Young TB. The relation between cigarette smoking and sleep disturbance. Prev Med. 1994;23(3):328-334.

121. Soldatos CR, Kales JD, Scharf MB, Bixler EO, Kales A. Cigarette smoking associated with sleep difficulty. Science. 1980;207(4430): 551-553.

122. Zhang L, Samet J, Caffo B, Punjabi NM. Cigarette smoking and nocturnal sleep architecture. Am J Epidemiol. 2006;164(6):529-537.

123. Peters EN, Fucito LM, Novosad C, Toll BA, O'Malley SS. Effect of night smoking, sleep disturbance, and their co-occurrence on smoking outcomes. Psychol Addict Behav. 2011;25(2):312-319.

124. Lavigne GL, Lobbezoo F, Rompré PH, Nielsen TA, Montplaisir J. Cigarette smoking as a risk factor or an exacerbating factor for restless legs syndrome and sleep bruxism. Sleep. 1997;20(4):290-293.

125. Casasola GG, Álvarez-Sala JL, Marques JA, Sánchez-Alarcos JMF, Tashkin DP, Espinós D. Cigarette smoking behavior and respiratory alterations during sleep in a healthy population. Sleep Breath. 2002;6(1):19-24.

126. Birkett NJ. Trends in smoking by birth cohort for births between 1940 and 1975: A reconstructed cohort analysis of the 1990 Ontario health survey. Prev Med. 1997;26(4):534-541.

127. Schepis TS, Rao U. Epidemiology and etiology of adolescent smoking. Curr Opin Pediatr. 2005;17(5):607-612.

128. Negriff S, Dorn LD, Pabst SR, Susman EJ. Morningness/eveningness, pubertal timing, and substance use in adolescent girls. Psychiatry Res. 2011;185(3):408-413.

129. Noland H, Price JH, Dake J, Telljohann SK. Adolescents' sleep behaviors and perceptions of sleep. J Sch Health. 2009;79(5):224-230.

130. Catrett CD, Gaultney JF. Possible insomnia predicts some risky behaviors among adolescents when controlling for depressive symptoms. J Genet Psychol. 2009;170(4):287-309.

131. Czeisler CA, Richardson GS, Coleman RM, et al. Chronotherapy: resetting the circadian clocks of patients with delayed sleep phase insomnia. Sleep. 1981;4(1):1-21.

132. Levi F. Circadian chronotherapy for human cancers. Lancet Oncol. 2001;2(5):307-315.

133. Hermida RC, Ayala DE, Fernandez JR, Calvo C. Chronotherapy improves blood pressure control and reverts the nondipper pattern in patients with resistant hypertension. Hypertension. 2008;51(1):69-76.

134. Pincus DJ, Humeston TR, Martin RJ. Further studies on the chronotherapy of asthma with inhaled steroids: The effect of dosage timing on drug efficacy. J Allergy Clin Immunol. 1997;100(6 Pt 1):771-774.

135. Akerstedt T. Psychological and psychophysiological effects of shift work. Scand J Work Environ Health. 1990;16 Suppl 1:67-73.

136. Smith-Coggins R, Howard SK, Mac DT, et al. Improving alertness and performance in emergency department physicians and nurses: The use of planned naps. Ann Emerg Med. 2006;48(5):596-604. e3.

137. Lovato N, Lack L, Ferguson S, Tremaine R. The effects of a 30-min nap during night shift following a prophylactic sleep in the afternoon. Sleep Biol Rhythms. 2009;7(1):34-42. 
138. Blask DE, Brainard GC, Dauchy RT, et al. Melatonin-depleted blood from premenopausal women exposed to light at night stimulates growth of human breast cancer xenografts in nude rats. Cancer Res. 2005;65(23):11174-11184.

139. Kayumov L, Casper RF, Hawa RJ, et al. Blocking low-wavelength light prevents nocturnal melatonin suppression with no adverse effect on performance during simulated shift work. J Clin Endocrinol Metab. 2005;90(5):2755-2761.

140. Crowley SJ, Lee C, Tseng CY, Fogg LF, Eastman CI. Combinations of bright light, scheduled dark, sunglasses, and melatonin to facilitate circadian entrainment to night shift work. J Biol Rhythms. 2003;18(6):513-523.

141. Zee PC, Goldstein CA. Treatment of shift work disorder and jet lag. Curr Treat Options Neurol. 2010;12(5):396-411.

142. Johansson K, Hemmingsson E, Harlid R, et al. Longer term effects of very low energy diet on obstructive sleep apnoea in cohort derived from randomised controlled trial: prospective observational follow-up study. BMJ. 2011;342:d3017. doi: 10.1136/bmj.d3017.

143. Tuomilehto HPI, Seppa JM, Partinen MM, et al. Lifestyle intervention with weight reduction: first-line treatment in mild obstructive sleep apnea. Am J Respir Crit Care Med. 2009;179(4):320-327.

144. Payne JK, Held J, Thorpe J, Shaw H. Effect of exercise on biomarkers, fatigue, sleep disturbances, and depressive symptoms in older women with breast cancer receiving hormonal therapy. Oncol Nurs Forum. 2008;35(4):635-642.

145. Gary R, Lee SYS. Physical function and quality of life in older women with diastolic heart failure: effects of a progressive walking program on sleep patterns. Prog Cardiovasc Nurs. 2007;22(2):72-80.

146. Tworoger SS, Yasui Y, Vitiello MV, et al. Effects of a yearlong moderate-intensity exercise and a stretching intervention on sleep quality in postmenopausal women. Sleep. 2003;26(7):830-836.
147. Irwin MR, Olmstead R, Motivala SJ. Improving sleep quality in older adults with moderate sleep complaints: a randomized controlled trial of tai chi chih. Sleep. 2008;31(7):1001-1008.

148. Li F, Fisher KJ, Harmer P, Irbe D, Tearse RG, Weimer C. Tai chi and self-rated quality of sleep and daytime sleepiness in older adults: A randomized controlled trial. J Am Geriatr Soc. 2004;52(6): 892-900

149. Davis CL, Tkacz J, Gregoski M, Boyle CA, Lovrekovic G. Aerobic exercise and snoring in overweight children: A randomized controlled trial. Obesity (Silver Spring). 2006;14(11):1985-1991.

150. Werch CE, Bian H, Carlson JM, et al. Brief integrative multiple behavior intervention effects and mediators for adolescents. J Behav Med. 2011;34(1):3-12.

151. Cain N, Gradisar M, Moseley L. A motivational school-based intervention for adolescent sleep problems. Sleep Med. 2011;12(3):246-251.

152. Moseley L, Gradisar M. Evaluation of a school-based intervention for adolescent sleep problems. Sleep. 2009;32(3):334-341.

153. Paine S, Gradisar M. A randomised controlled trial of cognitivebehaviour therapy for behavioural insomnia of childhood in schoolaged children. Behav Res Ther. 2011;49(6-7):379-388.

154. McAllister EJ, Dhurandhar NV, Keith SW, et al. Ten putative contributors to the obesity epidemic. Crit Rev Food Sci Nutr. 2009;49(10):868-913.

155. Kuhl ES, Clifford LM, Stark LJ. Obesity in preschoolers: Behavioral correlates and directions for treatment. Obesity (Silver Spring). 2012;20(1):3-29.
Nature and Science of Sleep

\section{Publish your work in this journal}

Nature and Science of Sleep is an international, peer-reviewed, open access journal covering all aspects of sleep science and sleep medicine, including the neurophysiology and functions of sleep, the genetics of sleep, sleep and society, biological rhythms, dreaming, sleep disorders and therapy, and strategies to optimize healthy sleep. The journal welcomes

\section{Dovepress}

original research, clinical \& epidemiological studies, reviews \& evaluations, case reports and extended reports. The manuscript management system is completely online and includes a very quick and fair peerreview system, which is all easy to use. Visit http://www.dovepress.com/ testimonials.php to read real quotes from published authors. 